\title{
Effect of Parental Divorce and Separation on Psychosocial Wellbeing of Adolescents in Kajiado North Sub-County, Kenya
}

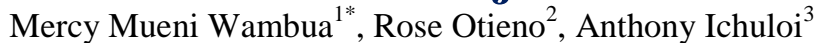

\author{
${ }^{1,2}$ Department of Psychology, Kisii University, P. O. Box 408-40200, Kisii, Kenya \\ ${ }^{3}$ Department of Philosophy and Religious Studies, Kisii University, P. O. Box 408-40200, Kisii, Kenya
}

DOI: $10.36347 /$ sjahss.2021.v09i05.008

| Received: 13.04.2020 | Accepted: 21.05.2021 | Published: 24.05.2021

*Corresponding author: Mercy Mueni Wambua

\section{Abstract}

Parental divorce and separation has become prevalent in Kenya, especially among young couples in metropolitan areas. Despite this fact, very few studies have been conducted to evaluate the impact of parental divorce and separation on children's psychosocial well-being. Therefore, the study investigated the effect of parental divorce and separation on psychosocial wellbeing of adolescents in selected secondary schools in Kajiado North Sub-County, Kenya. The study adopted a descriptive survey research design. It was conducted in Kajiado North Sub-County in Kajiado County. The target population for the study was all the school counsellors and Form Two students in day secondary schools in the five wards/zones of Kajiado North Sub-County. At the time of the study, there were 1312 Form Two students in the Sub-County and 11 heads of guidance and counselling departments. School context was chosen because it creates social networks in which the powerful peer and family processes of adolescence operate. Purposive sampling was employed to select the study area and the participating schools. Random and stratified sampling methods were then used to select student participants. Using stratified proportionate sampling and Stein's method, the study arrived at 298 student respondents and 11 school counsellors. Data was collected using students' questionnaire and the counsellors' interview schedule. Quantitative data was analysed using descriptive statistics and with the aid of the Statistical Package for Social Sciences (SPSS, version 23). Descriptive statistics included frequencies, means and standard deviation while Chi-square analysis was used to test for the hypotheses. From the results of the study, parental divorce and separation had impaired with children's psychosocial well-being. It was recommended that as part of a public education programme designed to raise awareness about the hazards of divorce for children, attention should focus on the specific hazards caused by high conflict situations. There is also a need to help parents with skills to deal with the effects of divorce and separation on the psychosocial well-being of children. More research should be conducted on the predisposing factors of parental divorce and separation among Kenya's young families.

Keywords: Parental Divorce, Separation, Psychosocial Wellbeing, Adolescent Children, Kajiado, Kenya.

Copyright $\odot 2021$ The Author(s): This is an open-access article distributed under the terms of the Creative Commons Attribution 4.0 International License (CC BY-NC 4.0) which permits unrestricted use, distribution, and reproduction in any medium for non-commercial use provided the original author and source are credited.

\section{INTRODUCTION}

Continuous presence of both parents during the marriage course is beneficial for development of a child across all domains [1]. When a mother and father work harmoniously together during parenting, they cooperatively provide encouragement, support and access to activities that enable their children to master key developmental tasks for life. They do this by providing the necessary support for a child to safely and productively explore and learn from their environment at home, neighbourhood and cultural realm. These reallife experiences and exposures directly or indirectly shape a child's behaviour. This way a child is modelled to adapt behaviours that ensures they operate within the expectation of their society.
Studies indicate that psychosocial wellbeing is a key ingredient in a child's development and functioning [2]. Their ability to have cognitive, emotional and spiritual strengths, combined with positive social relationships, is necessary to motivate the development of life skills, which then allow children to understand and engage with different environments. Moreover, it allows them to make healthy choices, which instils in the children hope about their future. Well-functioning marriages also impart a sense of security and psychosocial wellbeing in children [1]. Adolescent children especially benefit more where parents are not separated or divorced. When parents cooperate to rear children, they empower the children to explore their environment, give them warmth and love, provide proper socialization and physical needs. 
Cases of parental divorce and separation are on the rise in the world currently. In the United States of America, parental divorce and separation rates doubled from 0.8 per 1000 person in 1965 to 1.9 in 2015 [3]. Jackson, Rogers and Sartor [4] posit that the alarming high number of divorce and separation cases could be explained by the popularity or acceptance of parental divorce, hence normalization of divorce and separation, in many societies. This normalization has created the illusion that children of parents who divorce and separate do not experience negative effects as a result. However, in a study, Wolf [5] has found that parental divorce and separation in the USA causes anxiety, depression, triangulation, decreased social functioning as well as poor self-regulation among adolescent children. This sentiment echoes that of Rose [6], who, based on a legal perspective, argues that counselling is mandatory to both divorced parents and affected children.

\section{Parental divorce/separation and psychosocial wellbeing of adolescent children}

In Sweden, a study by Gähler and Palmtag [7] found that children of divorced parents did not fare well in both psychological and social parameters of wellbeing. They noted that such children scored poorly on psychological well-being indicators such as selfconcept and self-confidence, optimism, problemsolving, concentration, emotional stability and selfcontrol among others. Most of these children claimed that their living conditions had greatly deteriorated since their parents had divorced. Their educational needs had also been greatly impaired by the negative psychosocial outcomes of parental divorce. The work of Gähler and Palmtag was undertaken in Sweden while the present study was conducted in Kenya.

According to Amato [8], overall, most studies have sought to define the effect of divorce and separation on the well-being of children by examining the differences in conduct between children of divorced parents and those from two-parent homes. These studies have consistently concluded that children of divorced parents exhibit more conduct problems, emotional imbalances, and difficulty establishing and maintaining social relationships compared to their counterparts from two-parent families. Amato's study relies on a systematic review of literature while the current study relied on empirical evidence obtained from children of divorced parents in Kajiado North Sub-County in Kenya.

Anderson [9] examined the effect of changes in family structure caused by parental divorce on the overall well-being of children. Among the effects that have implications on psychosocial well-being of children are: loss of time with parent, loss of emotional security, stunting of their emotional and psychological development, changes in attitudes about sex, loss of academic stimulation, loss of religious convictions, poor physical health and emotional distress. Anderson's views helped the present study to identify the effects of parental divorce and separation on children's psychosocial well-being in Kajiado North Sub-County.

Uphold-Carrier and Utz [10] studied the longterm psychological impact of parental divorce on young and adult children. They established that children of divorced parents were more likely to suffer depression, as shown by their constant restlessness, hyperactivity and extreme mood swings. They however found that the age at which a child experienced divorce was a factor in the extent of resultant depressive tendencies. In other words, children who experienced parental divorce at a younger age tended to suffer from severe forms of depression compared to those who experienced it at a later age. Although the present study did not explore the relative difference of effects of parental divorce and separation with respect to children's ages, it benefited from the reviewed study by identifying the overall impact of divorce on children's psychosocial wellbeing.

D'Onforio and Emery [11] posit that family disruptions constitute some major precursors of health problems for children. Among the most salient symptoms of such health problems are depressed moods, complaints of stomach and headaches or a general feeling of sickness. Juang et al. [12] also found that children of divorced parents often complained of headaches, which were attributed to increased distress. The reviewed work provided a useful dimension on the effects of parental divorce by emphasizing the effects of marital disintegration on the physical health of children.

Hamama and Ronen-Shenhav [13] studied self-control, social support and aggression among adolescents from divorced and two-parent homes. They found a strong relationship between parental divorce and the tendency to develop angry feelings and harbour hostile thoughts among adolescents. They also found that enhanced self-control and social assistance helped these adolescents to cope with the negative psychological effects of parental divorce. Therefore, they concluded that mitigation strategies to enhance the psychosocial well-being of adolescents whose parents have divorced should focus on helping them to build strong self-control and provide them with social assistance. In light of such findings, the present study examined the effect of parental divorce and separation on the psychological well-being of adolescents.

Kleinsorge and Covitz [14] aver that, owing to the effects of parental divorce, most adolescents resort to delinquency, self-isolation, substance abuse, sexual misadventures and poor academic performance. They also noted that boys of separated or divorced parents tend to idealize suicide and personal recklessness. In their study, Larsson, Dilshad, Lichtenstein and Barker 
[15] also associated aspects of attention deficit or hyperactivity in children with parental divorce.

According to Morin [16], divorce causes emotional effects on children, no matter how much parents take precaution to protect them. For younger children, divorce makes them confused, especially when they have to keep moving from one parent's house to the next. Younger children mostly worry that if their parents stop loving themselves, then they (parents) could also stop loving them (children). Older children worry that divorce might be a result of them or their own mistakes or misbehaviour. On their part, adolescents feel disappointed and angry with the situation of divorce in general. They might particularly direct their anger at one or both parents for the chaos engendered by divorce in their lives. All these experiences translate into psychological distress for children of divorced parents.

Cohen and Weitzman [17] also identify ages of children as a variant in the degree of effect of divorce. However, they note that divorce does affect even infants to some degree. According to these authors, infants notice the changes in the common routines and such changes can cause psychological distress to them. Consequently, younger children tend to be irritable, restless and depressed during parental divorce.

Al-Fayez, Ohaeri and Gado [18], in their study, found that children from divorced families also had a great propensity towards suicidal tendencies. These tendencies are evidenced by their ever-present state of sadness and emotional eruptions. Such children also tend to isolate themselves from the others or opt to wander away from their parents and other adults. These authors also noted that, because such children prefer to be alone, they are easily prone to exploitation by adults with unsavoury character. They therefore link children's risk of abuse with parental divorce and separation.

Haimi and Lerner [19] undertook a systematic review of studies on the impact of divorce on children's well-being. They reported that children of divorced parents in general had difficulties focusing on their academic studies, exhibited increased behavioural problems, low self-concept, increased social problems with peers and difficulty seeing eye-to-eye with parents.

Studies by Amato [20], Amato and Fowler [21] and Kelly and Emery [22] identified several explanations for the problems of well-being among children of divorced parents. First, parents are often too busy contending with their own loss of spouses and marriage to notice or address the effects of divorce on their children. Second, economic losses often implies that one parent gets more financially stable than the other. If the children are also subdivided between the spouses, it means that some of the children will be better placed than the others. Third, there is the general stress caused by divorce, owing to numerous changes such as moving schools and relocating, among others. Fourth, most parents are generally not skilled in matters of raising children, let alone help the children mitigate the effects of divorce on the children. Lastly, at any stage of the divorce process, children must be exposed to the ensuing conflict between the parents. Such exposure will definitely have a negative impact on the children's well-being.

\section{Statement of the problem}

Legal, cultural and social reasons have been advanced to justify divorce and separation among couples. There are indications that the practice is gaining wide acceptance in Kenya. Ideally, this increasing acceptance of divorce and separation in society ought to go hand in hand with targeted programmes designed to reduce the negative impacts of divorce and separation on children. However, there are indication that there are hardly any programmes in place that aim at: increasing the self-sufficiency of single parents arising from divorce; reducing conflict between parents, and making use of support groups outside the immediate family. It is apparent therefore that normalisation of divorce and separation are done in total disregard of their negative psychosocial effects on children who find themselves in the middle of conflicting parents. Consequently, owing to increasing cases of parental divorce and separation, many adolescent children are being exposed to diverse stressors that challenge their development across all domains. If this state of affairs persists, such children could suffer for many years from psychological and social difficulties associated with these stressors. Such difficulties include anxiety when forming enduring attachments at later developmental stages of life.

In light of the above realities, this study sought to investigate the effect of parental divorce and separation on the psychosocial wellbeing of adolescents in selected secondary schools in Kajiado North SubCounty. A preliminary review of statistics revealed that the Sub-County's divorce and separation rates were higher than both the national and county rates at $1.52 \%$, with the national rate being $1.48 \%$ and county rate being $0.01 \%$ (Kenya National Bureau of Statistics [KNBS] [23]. These figures attested to the fact that more adolescent children in the Sub-County experienced the effects of divorce related vulnerabilities than their counterparts in other areas of the County or nation. Despite the high levels of divorce and separation in the Sub-County, there was scarce literature to describe the reasons for the high prevalence, the effects of parental divorce and separation on the adolescent children as well as existing coping mechanisms to help mitigate and recover from the negative effects of parental divorce and separation. It is against this background that this paper examines the effect of parental divorce and separation effects on 
adolescent children's psychosocial wellbeing in Kajiado North Sob-County in Kenya.

\section{MATERIALS AND METHODS}

The study was conducted in Kajiado North Sub-County in Kajiado County. It is a vast sub-county characterised by urban, peri-urban as well as rural population. A study by Omoro [24] indicates that Nairobi metropolitan area (Kajiado north falls within it) experiences high rates of separation and divorce. Therefore, the choice of study area was informed by high levels of the phenomenon to be studied. The study adopted a descriptive survey research design. The target population for the study was all the school counsellors and Form Two students in day secondary schools in the five wards/zones of Kajiado North Sub-County. At the time of study, there were 1312 Form Two students and 11 heads of guidance and counselling departments in the Sub-County. All the Form Two students and the counsellors in their respective schools were purposively selected. In addition, random and stratified sampling methods were used to select student participants to be involved in the study. In addition, random and stratified sampling methods were used to select student participants to be involved in the study. Out of this population, the final sample size was determined by employing Stein's method, which generated a sample size of 298 .

The research data was collected using students' questionnaire and the counsellors' interview schedule. The filled and returned questionnaires were inspected for cleaned. They were then coded and entered into a database designed using the Statistical Package for Social Sciences (SPSS, v.23). Data was then analysed by use of both descriptive and inferential statistics. This involved frequencies, means and standard deviation in summarizing the data. Chi-square analysis was adopted to check for association between the independent and dependant variables. Results were considered significant at $95 \%$ confidence level. Data presentation was done using tables, bar graphs and pie charts. In addition, qualitative data from interview schedules was embedded into quantitative discussions in order to answer the "why" and "how", thus making the final report exhaustive.

\section{RESULTS AND DISCUSSION}

The study sought to explore the effect of parental divorce and separation on psychosocial wellbeing of adolescent children in selected secondary schools in Kajiado North Sub-County. Table 1 presents the study results.

Table-1: Effect of Divorce/Separation on Psychosocial Wellbeing for Adolescent Children

\begin{tabular}{|c|c|c|c|c|c|c|c|c|c|}
\hline $\begin{array}{l}\text { Children who have experienced parental } \\
\text { divorce and separation: }\end{array}$ & & SD & D & $\mathbf{N}$ & $\mathbf{A}$ & SA & Total & Mean & $\begin{array}{l}\text { Std. } \\
\text { Dev }\end{array}$ \\
\hline \multirow{2}{*}{$\begin{array}{l}\text { Are restless, overactive and cannot sit still for } \\
\text { long }\end{array}$} & $\mathrm{F}$ & 15 & 45 & 23 & 100 & 73 & 256 & 3.67 & 1.23 \\
\hline & $\%$ & 5.9 & 17.6 & 9.0 & 39.1 & 28.5 & 100.0 & & \\
\hline \multirow{2}{*}{$\begin{array}{l}\text { Often complain of headaches, stomach-aches } \\
\text { or sickness }\end{array}$} & $\mathrm{F}$ & 14 & 62 & 35 & 45 & 100 & 256 & 3.61 & 1.36 \\
\hline & $\%$ & 5.5 & 24.2 & 13.7 & 17.6 & 39.1 & 100.0 & & \\
\hline \multirow[t]{2}{*}{ Often have temper tantrums } & $\mathrm{F}$ & 14 & 31 & 39 & 78 & 94 & 256 & 3.81 & 1.21 \\
\hline & $\%$ & 5.5 & 12.1 & 15.2 & 30.5 & 36.7 & 100.0 & & \\
\hline \multirow{2}{*}{$\begin{array}{l}\text { Are rather solitary, tends to do their things } \\
\text { alone }\end{array}$} & $\mathrm{F}$ & 16 & 23 & 35 & 86 & 96 & 256 & 3.87 & 1.19 \\
\hline & $\%$ & 6.3 & 9.0 & 13.7 & 33.6 & 37.5 & 100.0 & & \\
\hline \multirow{2}{*}{ Have many worries; often seem worried } & $\mathrm{F}$ & 15 & 20 & 20 & 103 & 98 & 256 & 3.97 & 1.14 \\
\hline & $\%$ & 5.9 & 7.8 & 7.8 & 40.2 & 38.3 & 100.0 & & \\
\hline \multirow{2}{*}{$\begin{array}{l}\text { Are easily distracted; suffer concentration } \\
\text { wanders }\end{array}$} & $\mathrm{F}$ & 12 & 22 & 43 & 75 & 104 & 256 & 3.93 & 1.16 \\
\hline & $\%$ & 4.7 & 8.6 & 16.8 & 29.3 & 40.6 & 100.0 & & \\
\hline \multirow[t]{2}{*}{ Are often unhappy, downhearted or tearful } & $\mathrm{F}$ & 12 & 15 & 16 & 90 & 123 & 256 & 4.16 & 1.09 \\
\hline & $\%$ & 4.7 & 5.9 & 6.3 & 35.2 & 48.0 & 100.0 & & \\
\hline \multirow[t]{2}{*}{ Steal from home, school or elsewhere } & $\mathrm{F}$ & 7 & 51 & 40 & 39 & 119 & 256 & 3.83 & 1.28 \\
\hline & $\%$ & 2.7 & 19.9 & 15.6 & 15.2 & 46.5 & 100.0 & & \\
\hline
\end{tabular}

Table 1 shows that $73(28.5 \%)$ of the respondents strongly agreed, $100(39.1 \%)$ agreed, $23(9.0 \%)$ were undecided, $45(17.6 \%)$ disagreed and $15(5.9 \%)$ strongly disagreed with the statement that children who had experienced parental divorce and separation were restless, overactive and could not sit still for long. Further, the mean scores and standard deviation showed that the respondents agreed with the statement (Mean=3.67, Std. dev=1.23). As such, it was deduced that children who had experienced parental divorce and separation were restless, overactive and could not sit still for long.

Moreover, $100(39.1 \%)$ of the respondents strongly agreed, 45(17.6\%) agreed, 35(13.7\%) were undecided, 62(24.2\%) disagreed and 14(5.5\%) strongly disagreed with the statement that children who had experienced parental divorce and separation often complained of headaches, stomach-aches or sickness. Further, the means and standard deviation showed that the respondents agreed with the statement (Mean=3.61, 
Mercy Mueni Wambua et al., Sch J Arts Humanit Soc Sci, May, 2021; 9(5): 194-200

Std. dev=1.21), meaning that children who had experienced parental divorce and separation often suffered from headaches, stomach-aches or sickness.

Additionally, 94(36.7\%) of the respondents strongly agreed, $78(30.5 \%)$ agreed, 39(15.2\%) were undecided, 31(12.1\%) disagreed and 14(5.5\%) strongly disagreed with the statement that children who had experienced parental divorce and separation often had temper tantrums. The means and standard deviation showed that the respondents agreed with this statement (Mean=3.81, Std. dev=1.21). These findings suggested that children who had experienced parental divorce and separation often had temper tantrums.

Further, 96(37.5\%) of the respondents strongly agreed, 86(33.6\%) agreed, 35(13.7\%) were undecided, $23(9 \%)$ disagreed and $16(16.3 \%)$ strongly disagreed with the statement that children who had experienced parental divorce and separation were rather solitary, tended to do their things alone. Further, the means and standard deviation showed that the respondents agreed with the statement (Mean=3.87, Std. dev=1.19). This implied that children who had experienced parental divorce and separation tended to prefer being alone and doing things on their own.

On the statement that children who had experienced parental divorce and separation had many worries or often seemed worried, $98(38.3 \%)$ of the respondents strongly agreed, 103(40.2\%) agreed, $20(7.8 \%)$ were undecided, $20(7.8 \%)$ disagreed and $15(5.9 \%)$ strongly disagreed. Further, the means and standard deviation showed that the respondents agreed with the statement (Mean=3.97, Std. dev=1.14). This implied that children who had experienced parental divorce and separation exhibited tendencies to worry.

Furthermore, 104(40.6\%) of the respondents strongly agreed, 75(29.3\%) agreed, 43(16.8\%) were undecided, 22(8.6\%) disagreed and 12(4.7\%) strongly disagreed with the statement that children who had experienced parental divorce and separation were easily distracted or suffered from concentration wanders. The means and standard deviation also indicated that the respondents agreed with the statement $($ Mean=3.93, Std. dev=1.16). These findings suggested that children who had experienced parental divorce and separation were easily distracted or easily lost their concentration.

Finally, 123(48\%) of the respondents strongly agreed, 90(35.2\%) agreed, 16(6.3\%) were undecided, $15(5.9 \%)$ disagreed and $12(4.7 \%)$ strongly disagreed with the statement that children who had experienced parental divorce and separation were often unhappy, downhearted or tearful. Further, the means and standard deviation showed that majority of the respondents agreed with the statement (Mean=4.16, Std. dev=1.09). This implied that children who had experienced parental divorce and separation were often unhappy, downhearted or tearful.

The above study results underscored that parental divorce and separation had had a negative influence on psychosocial wellbeing of adolescent children in selected secondary schools in Kajiado North Sub-County. Therefore, children who had experienced parental divorce and separation tended to be restless, overactive, could not sit still for long and often had temper tantrums. Moreover, these children often complained of headaches, stomach aches or sickness. They also tended to prefer solitary moments, to do their things alone and often seemed worried. Additionally, these children were easily distracted and lacked concentration. Lastly, these children were often unhappy, downhearted or tearful.

The findings of the study on the effects of parental divorce and separation on the psychological well-being of children were in concurrence with those of various scholars. For instance, Amato [8] observed that most studies have sought to define the effect of divorce and separation on the well-being of children by examining the differences in conduct between children of divorced parents and those from two-parent homes. These studies have consistently concluded that children of divorced parent's exhibit more conduct problems, emotional imbalances, and difficulty establishing and maintaining social relationships compared to their counterparts from two-parent families.

Similarly, Anderson [9] reported that have implications on psychosocial well-being of children are: loss of time with parent, loss of emotional security, stunting of their emotional and psychological development, changes in attitudes about sex, loss of academic stimulation, loss of religious convictions, poor physical health and emotional distress.

Moreover, Uphold-Carrier and Utz [10] found that children of divorced parents were more likely to suffer depression, as shown by their constant restlessness, hyperactivity and extreme mood swings. They however found that the age at which a child experienced divorce was a factor in the extent of resultant depressive tendencies. In other words, children who experienced parental divorce at a younger age tended to suffer from severe forms of depression compared to those who experienced it at a later age.

Additionally, Hamama and Ronen-Shenhav [13] found a strong relationship between parental divorce and the tendency to develop angry feelings and harbour hostile thoughts among adolescents. They also found that enhanced self-control and social assistance helped these adolescents to cope with the negative psychological effects of parental divorce. Therefore, they concluded that mitigation strategies to enhance the psychosocial well-being of adolescents whose parents 
have divorced should focus on helping them to build strong self-control and provide them with social assistance. In light of such findings, the present study examined the effect of parental divorce and separate on the psychological well-being of adolescents.

Al-Fayez et al. [18] also found that children from divorced families also had a great propensity towards suicidal tendencies. These tendencies are evidenced by their ever-present state of sadness and emotional eruptions. Such children also tend to isolate themselves from the others or opt to wander away from their parents and other adults. These authors also noted that, because such children prefer to be alone, they are easily prone to exploitation by adults with unsavoury character. They therefore link children's risk of abuse with parental divorce and separation.

Other studies, such as Amato [20], Amato and Fowler [21] and Kelly and Emery [22], identified several explanations for the problems of well-being among children of divorced parents. First, parents are often too busy contending with their own loss of spouses and marriage to notice or address the effects of divorce on their children. Second, economic losses often imply that one parent gets more financially stable than the other. If the children are also subdivided between the spouses, it means that some of the children will be better placed than the others. Third, there is the general stress caused by divorce, owing to numerous changes such as moving schools and relocating, among others. Fourth, most parents are generally not skilled in matters of raising children, let alone help the children mitigate the effects of divorce on the children. Lastly, at any stage of the divorce process, children must be exposed to the ensuing conflict between the parents. Such exposure will definitely have a negative impact on the children's well-being.

\section{CONCLUSION AND RECOMMENDATIONS}

Overall, children who had experienced parental divorce and separation tend to be restless, overactive and could not sit still for long. Moreover, they suffer from headaches, stomach-aches or sickness. They also often have temper tantrums; prefer being alone and doing things on their own. Additionally, tend to be in a constant state of worry and are easily distracted or easily lose concentration. Finally, children who had experienced parental divorce and separation are often unhappy, downhearted or tearful.

From the reviewed literature, it was noted that there are many strategies that have been proposed by experts as ways to alleviate the severity of the effects of parental divorce on the well-being of the child. Out of those strategies, this study recommends involvement and full disclosure of the divorce process to the children. Parents must be open to answer all questions the children ask. They must also allow the children to express their disappointment.

\section{REFERENCES}

1. Ajidahun, B. O. (2011). Impact of Psychosocial Factors on the Adolescents' Behaviour. Creative Education, 2(4), 398.

2. Seligman, M.E.P. (2011). Flourish. New York, NY: Simon \& Schuster.

3. Eurostat. (2015). Marriage and Divorce Statistics. Available

from: https://epp.eurostat.ec.europa.eu/statisticsexplained/index.php/Marriage-and-divorcestatistics

4. Jackson, K. M., Rogers, M. L., \& Sartor, C. E. (2016). Parental divorce and initiation of alcohol use in early adolescence. Psychology of addictive behaviors, 30(4), 450.

5. Wolf, B. (2016). Psychosocial and academic implications of divorce on adolescents: A Social Work perspective.

6. Rose, S. R. (2009). A review of effectiveness of group work with children of divorce. Social Work with Groups, 32(3), 222-229.

7. Gähler, M., \& Palmtag, E. L. (2015). Parental divorce, psychological well-being and educational attainment: Changed experience, unchanged effect among Swedes born 1892-1991. Social Indicators Research, 123(2), 601-623.

8. Amato, P. R. (2014). The consequences of divorce for adults and children: An update. Društvena istraživanja: časopis za opća društvena pitanja, 23(1), 5-24.

9. Anderson, J. (2014). The impact of family structure on the health of children: Effects of divorce. The Linacre Quarterly, 81(4), 378-387.

10. Uphold-Carrier, H., \& Utz, R. (2012). Parental divorce among young and adult children: A longterm quantitative analysis of mental health and family solidarity. Journal of Divorce \& Remarriage, 53(4), 247-266.

11. D'Onofrio, B., \& Emery, R. (2019). Parental divorce or separation and children's mental health. World Psychiatry, 18(1), 100.

12. Juang, K. D., Wang, S. J., Fuh, J. L., Lu, S. R., \& Chen, Y. S. (2004). Association between adolescent chronic daily headache and childhood adversity: a community-based study. Cephalalgia, 24(1), 54-59.

13. Hamama, L., \& Ronen-Shenhav, A. (2012). Selfcontrol, social support, and aggression among adolescents in divorced and two-parent families. Children and Youth Services Review, 34(5), 1042-1049.

14. Kleinsorge, C., \& Covitz, L. M. (2012). Impact of divorce on children: developmental considerations. Pediatrics in review, 33(4), 147-54.

15. Larsson, H., Dilshad, R., Lichtenstein, P., \& Barker, E. D. (2011). Developmental trajectories of DSM- IV symptoms of attentiondeficit/hyperactivity disorder: Genetic effects, family risk and associated 
psychopathology. Journal of Child Psychology and Psychiatry, 52(9), 954-963.

16. Morin, A. (2019). The Psychological Effects of Divorce on Children. 2019. Available from: https://www.verywellfamily.com/psychologicaleffects-of-divorce-on-kids-4140170?print

17. Cohen, G. J., Weitzman, C. C., \& Committee on Psychosocial Aspects of Child and Family Health. (2016). Helping children and families deal with divorce and separation. Pediatrics, 138(6).

18. Al-Fayez, G. A., Ohaeri, J. U., \& Gado, O. M. (2012). Prevalence of physical, psychological, and sexual abuse among a nationwide sample of Arab high school students: association with family characteristics, anxiety, depression, self-esteem, and quality of life. Social psychiatry and psychiatric epidemiology, 47(1), 53-66.

19. Haimi, M., \& Lerner, A. (2016). The impact of parental separation and divorce on the health status of children, and the ways to improve it. J Clin Med Genomics, 4(1), 137.

20. Amato, P. R. (2000). The consequences of divorce for adults and children. Journal of marriage and family, 62(4), 1269-1287.

21. Amato, P. R., \& Fowler, F. (2002). Parenting practices, child adjustment, and family diversity. Journal of marriage and family, 64(3), 703-716.

22. Kelly, J. B., \& Emery, R. E. (2003). Children's adjustment following divorce: Risk and resilience perspectives. Family relations, 52(4), 352-362.

23. Kenya National Bureau of Statistics (KNBS). (2009). Kenya population and housing census. Nairobi: KNBS. 2010.

24. Omoro, P.M. (2018). Investigating the causes and possible solutions of divorce in Nairobi County, Kenya (Master's Thesis). University of Nairobi. 